\title{
A produção da saúde e a população do campo: uma experiência no assentamento de reforma agrária em Pernambuco - Brasil
}

\section{Health production and the rural population: an experiment in a settlement of agrarian reform in Pernambuco - Brazil}

\section{Producción de salud y población rural: un experimento en un asentamiento de la reforma agraria em Pernambuco - Brasil}

Marina Fenicio Soares BATISTA ${ }^{1}$ Paulette Cavalcanti de ALBUQUERQUE ${ }^{2}$

\section{RESUMO}

Este estudo objetiva analisar a produção da saúde no campo, a partir de vivências em assentamento rural vinculado ao Movimento dos Trabalhadores Sem Terra (MST), na Região Metropolitana de Recife, Pernambuco. O estudo é fruto de um projeto de extensão desenvolvido por residentes em saúde da família e saúde coletiva, que visava a fomentar a visibilidade dessa população, vivenciando na prática o que é ser camponês, dialogando com a promoção à saúde, a educação popular e os princípios do movimento em articulação. O projeto foi construído com o setor saúde do MST-PE e teve duração de 12 meses, nos quais se trabalhou o Diagnóstico Rural Participativo, entre outras atividades em encontros quinzenais. A partir das vivências e da análise documental das relatorias e outros documentos, buscou-se sistematizar a produção da saúde no campo, colocando-a em análise. Foram identificadas três categorias principais: organização, incluindo o trabalho em grupo e identidade camponesa; produção da saúde, incluindo sua percepção e determinantes; identidade e lutas da população assentada. Como resultados, considerou-se que a organização e mobilização do assentamento enquanto movimento estão adormecidas, mesmo sendo potentes; que ainda se referenciam em modelos de saúde biomédicos, relacionando saúde com assistência médica e que ações de promoção da saúde ou educativas referenciadas na Educação Popular são poucas, mas podem ser desenvolvidas. A potência do movimento e da articulação dele com as residências em saúde podem sinalizar na perspectiva de resignificação da saúde nos assentamentos e da construção de outros projetos como a Residência em Saúde no Campo.

1 Residente em Saúde da Família pelo Programa Residência Multiprofissional Integrada em Saúde da Família pela Universidade de Pernambuco, RIMISF/UPE. E-mail: marinafsb@gmail.com

2 Professora da Universidade de Pernambuco e pesquisadora da Fiocruz Pernambuco. 
Palavras-chave: promoção da saúde; saúde no campo; saúde da família; residência em saúde; educação popular.

\section{ABSTRACT}

This study aims to analyze the production of health in the field, from experiences in rural settlement linked to the Landless Workers Movement (MST) in the Metropolitan Region of Recife, Pernambuco. The study is the result of an extension project developed by residents (interns) in family health and community health, which aimed to promote the visibility of this population experiencing in practice what is being a peasant, in dialogue with health promotion, popular education and the principles of the movement. The project was built with the health sector of MST-PE and lasted 12 months, during which we worked the Participatory Rural Appraisal, among other activities in fortnightly meetings. From the experiences and documental analysis of reports and other documents, we sought to systematize the production of health in the rural areas, placing it under review. Three main categories were identified: the organization, including group work and peasant identity; production of health, including their perception and determinants; identity and struggles of the settler population. As a result, it was considered that the organization and mobilization of settlement as a movement are asleep, even though potent; that reference models lay still in biomedical health, relating health to medical care actions. There are few actions to promote health or education referenced in popular education, but they may be developed. The power of the movement and its integration with health internships may signal the prospect of reframing health in the settlements and the construction of other projects such as Health Internship in rural area.

Keywords: Health Promotion; Health Field; Family Health; Residence in health; Popular Education.

\section{RESUMEN}

Este estudio tiene como objetivo analizar la producción de salud en el campo desde las experiencias de asentamiento rural vinculadas al Movimiento de los Trabajadores Sin Tierra (MST) en la Región Metropolitana de Recife, Pernambuco. El estudio es el resultado de un proyecto de extensión desarrollado por los residentes en la salud familiar y salud de la comunidad, cuyo objetivo es promover la visibilidad de esta población. Experimentan en la práctica lo que es ser un campesino, en diálogo con la promoción de la salud, la educación popular y los principios movimiento en conjunto. El proyecto fue construido con el sector salud MST-PE y duró 12 meses, durante los cuales trabajó el Diagnóstico Rural Participativo entre otras actividades en las reuniones quincenales. De las experiencias y análisis documental de los relatores y de otros documentos, hemos tratado de sistematizar la producción de salud en el campo, colocándola en revisión. Se identificaron tres categorías principales: la organización, incluyendo el trabajo en grupo y la identidad campesina; la producción de la salud, incluyendo su percepción y determinantes; identidad y las luchas de la población del campo. Como resultado, se consideró que la organización 
y la movilización de asentamiento como un movimiento están dormidos, aunque sigan potentes; que todavía hacen referencia a los modelos de salud biomédica en relación con las acciones de salud y de atención médica. Las acciones de promoción de la salud o de la educación en salud son pocas, pero pueden desarrollarse. La potencia del y su integración con las residencias de salud pueden señalar la posibilidad de reformulación de la salud en los asentamientos y la construcción de otros proyectos como la residencia de la Salud en el campo.

Palabras clave: promoción de la salud; salud del campo; salud de la familia; residencia en la salud; educación popular.

\section{INTRODUÇÃO}

A população do campo, em específico no Brasil, além de ter grande influência econômica e social para o país, está marcada historicamente pela sua origem, por ter sido alvo de políticas de interesse agrário extrativista, da concentração de terras, do monocultivo e da pouca industrialização. Até hoje, os pequenos agricultores ainda são desvalorizados pela concepção histórica e pela distinção entre as grandes propriedades (propriedade capitalista) e pequenas propriedades (propriedade familiar), que o Brasil mantém e reforça ${ }^{1}$. Enquanto a propriedade capitalista tem como princípio a exploração dos trabalhadores que não possuem os instrumentos e materiais de trabalho nas grandes concentrações de terra, a propriedade familiar é instrumento direto de trabalho por quem a possui, ou seja, é propriedade do trabalhador ${ }^{1}$.

A partir desta diferenciação do camponês, possuidor de seus meios de produção, julgou-se importante conhecer o que caracteriza esta população do campo, organizada por um movimento social, na sua produção em saúde. Quais os hábitos, os contatos com o meio ambiente e com os meios de trabalho que norteiam o processo saúde-doença desta população? Exigem atenção diferenciada à saúde? Como resgatar as ações necessárias para que a saúde no campo seja efetiva, integral e um direito inerente a todos?

A saúde da população do campo no Brasil tem, em sua história, diversas caracterizações pelo seu meio de produção estar especificamente vinculado à terra. Contudo, os meios de produção para este fim sempre foram mais privilegiados pelo Estado do que as próprias condições de vida e de trabalho que o camponês estabelece com este meio em que vive.

De acordo com a Constituição Federal de 1988, o Estado, conjuntamente com a população, tem o dever de incentivar propostas que apontem para intensificar a produção de saúde no campo, por meio das melhorias das condições de vida, trabalho e prevenção de doenças. Essa concepção já vem sendo discutida desde 1950, com o surgimento das primeiras formas organizadas de trabalhadores rurais. Nas últimas décadas, os movimentos organizados ganharam força neste setor até que, em 2011, é lançada a Política Nacional de Saúde Integral das Populações do Campo e da Floresta (PNSIPCF). Tal política busca contribuir na ampliação do conceito de saúde, na afirmação 
desta como um direito, dependente de determinantes sociais, econômicos e culturais, políticos e ambientais, colaborando com o cumprimento do que é estabelecido na Constituição. ${ }^{2}$

É importante ressaltar que hábitos diferenciados, rotinas e processos de trabalhos característicos do campo necessitam de uma atenção especial da saúde, que, quando preconizada universalmente, deve respeitar os diferentes modos de vida ofertando práticas de saúde integrais, que não estejam somente vinculadas aos seres humanos, mas também com a terra. Para a população do campo, essa relação tem íntima afinidade com os meios de produção, com as condições sociais e de trabalho, com os processos que geram e mantêm a vida.

O objetivo deste estudo é analisar o que caracteriza a população do campo na produção de sua saúde, a partir da vivência com um movimento social, o Movimento dos Trabalhadores Sem Terra (MST), a fim de descrever as características que identificam a produção de saúde na população do campo, refletir sobre as propostas do MST para a produção de saúde no campo, expor as formas de cuidado em saúde pelos agricultores e familiares e refletir sobre a relação entre movimentos sociais e promoção à saúde.

São poucos os estudos sobre a saúde da população do campo, especialmente relacionados à ampliação do conceito de saúde e às formas de implementação da Política. Nesse sentido, é importante ratificar este conceito ampliado de saúde que, apoiado pelo Sistema Único de Saúde (SUS), deve ter apoio científico para assegurar atendimentos com qualidade e condições de acesso que priorizem a população do campo em sua especificidade. Estudos desse tipo podem subsidiar possíveis ações vinculadas à forma dinâmica que vivem e discutir as barreiras de acesso perante os serviços do SUS que ainda existem.

Com isso, investigar a produção da saúde é entender quais são os espaços de trocas e sua dimensão comunicacional para que a saúde seja efetivada, compreendendo onde as motivações interacionais localizam-se e como poderiam ser melhoradas, por meio da garantia desse direito, a fim de existir a liberdade em produzir saúde no campo.

Para isso, considerou-se necessário partir do embasamento teórico de como acontecem as relações de poder e produção econômica no campo, pois tais determinações relacionam-se com os modos de vida da população do campo em geral, e do assentamento onde ocorreu este estudo, em particular, e com os meios de produção em saúde que adotam.

\section{Desenvolvimento agrário e o neoliberalismo}

O Brasil, inserido na economia mundial no século XXI, presencia a fase do capitalismo financeiro globalizado, no qual a acumulação se dá através do capital financeiro, do mercado de ações, sob o controle dos bancos, que passam a comprar ações de médias e grandes empresas. Esse capital passa a controlar a produção de mercadorias (na indústria, na agricultura, nos minérios), 
para assim atribuir maior lucro da mais valia produzida pelos trabalhadores. ${ }^{3}$

Na agricultura, especificamente, o capital financeiro também foi gerando concentração, por meio da compra de ações de médias e grandes empresas de diferentes setores. Com isso, perpassa hoje toda a produção, desde as máquinas, os agrotóxicos e as ferramentas, as sementes, a organização das agroindústrias, o comércio, até o consumo. Adicionado a esta concentração, diversas regras mundiais foram impostas pela Organização Mundial do Comércio (OMC), Banco Mundial, Fundo Monetário Internacional, "normatizando o comércio de produtos agrícolas, de acordo com o interesse das grandes empresas, que obrigavam os governos a liberalizarem o comércio desses produtos". ${ }^{3}$

Esses subsídios, no Brasil, acontecem pelas isenções fiscais nas exportações ou importações para a grande produção agrícola. "Temos 50 maiores empresas transnacionais que controlam a maior parte da produção e comércio agrícola mundial". ${ }^{3}$ Com isso, pequenos agricultores necessitando de créditos bancários para sua produção não recebem financiamento se não obedecerem ao modo de produção agrícola imposto por essa agricultura industrial.

Os preços médios dos produtos agrícolas a nível internacional já não têm mais relação com o custo médio de produção e o valor real, medido pelo tempo de trabalho socialmente necessário. Mas, são resultados dos movimentos especulativos e do controle do oligopólio dos mercados agrícolas por essas grandes empresas. ${ }^{3}$

As grandes empresas dominadoras desses mecanismos compulsórios de comercialização das safras subjugam, desta forma, o produto dos lavradores, pois esses passam a trabalhar para as empresas, nos chamados "sistemas integrados", conservando a propriedade nominal da terra e mantendo a parcela principal, o lucro, com as empresas. Devido a isso, os preços dos produtos agrícolas nas cidades são altos. Em contrapartida, o pequeno agricultor recebe cada vez menos ${ }^{1}$, pois necessita comprar, a elevados preços, insumos como adubo, semente, fertilizante, inseticida, etc. "Na verdade, estamos diante da transferência de renda do pequeno agricultor para o grande capital". ${ }^{1}$

Para um pequeno agricultor conseguir ter condições plausíveis de trabalho e de vida, necessita de incentivos provenientes de políticas garantidas por leis. De acordo com o autor, embora seja reconhecido pelo governo que a maior parte da alimentação do Brasil é produzida pelos pequenos agricultores, poucos incentivos no âmbito nacional foram criados para estes produtores, inviabilizando a produção de recursos no campo e, consequentemente, sua produção de vida ${ }^{1}$.

E é essa precária condição de vida e de trabalho em que a população do campo permanece que denota a necessidade de articulação social na busca de direitos sociais:

Novas configurações de exclusão social presentes em nossa sociedade: se não mais prevalece o padrão de integração social via trabalho... é a partir dele que se explica a coesão social como um valor em si ou as forças de superação daquelas realidades 
sociais. $^{4}$

Nesse cenário, os movimentos sociais, principalmente na América Latina, estão vinculados à situação de carência em que se encontram os indivíduos nele engajados:

Noutros termos, é a situação de carência, como um processo subjetivo e individual que compreende escolhas entre carências diversas, que acaba sendo o fator nuclear que, de um modo geral, provoca a organização de determinados grupos em movimentos sociais, e que acaba por associá-los aos critérios de legitimado. ${ }^{4}$

Para a autora, estes são os novos sujeitos coletivos no cenário político, de diferentes espaços tradicionalmente definidos pela concepção liberal clássica de democracia, pois possuem como característica um forte traço de luta por conquistas na efetivação de demandas e direitos sociais, "conduzindo a grandes lutas reivindicativas contra um aparelho de dominação que rege cada vez mais o conjunto da sociedade, orientando-a para certo tipo de desenvolvimento, mas em nome da coletividade. $^{4}$

A implementação do neoliberalismo no Brasil reforça um novo modelo agrícola que deixa de desenvolver a indústria nacional para atender às demandas de um mercado externo, com o fornecimento de matérias primas agrícolas, consolidando a divisão mundial da produção de bens e do trabalho e o papel dos países do hemisfério Sul.

É nesse cenário político, histórico e cultural que o MST amplia essa discussão para questionar o modelo agrícola adotado pelo Brasil, que se utiliza do agronegócio para atender à subordinação ao capital financeiro, deixando clara a disputa existente entre diferentes e incompatíveis modelos agrícolas no país.

O movimento, que surge nos anos 80 com a ideia principal de democratizar a propriedade de terra, como uma forma de reprodução dos camponeses, de integrá-los ao mercado interno e de aumentar sua renda, melhorando assim a vida das famílias envolvidas, atualiza seu discurso e sua plataforma política.

Com isso, a discussão atual do Movimento dos Trabalhadores Sem Terra é de que essa disputa deixou de ser apenas pela ocupação de terras pelos camponeses, pois estes serão cooptados também pelo agronegócio que visa, por meio da compra ou do arrendamento, apossar-se dessas terras, a fim de atingir as demandas desse mercado externo. Passa a lutar por um novo modelo agrícola para o país, o que exige novas correlações de forças desses camponeses e os grandes proprietários rurais, o capital financeiro e as empresas transnacionais ${ }^{5}$.

Tal modelo visa a defender um novo programa de reforma agrária, que seja popular, não mais apenas dividindo a propriedade de terra, mas também construindo alianças entre todos os 
movimentos camponeses e desses com outros setores sociais envolvidos em mudanças estruturais. O objetivo é ampliar a luta pelo controle das sementes, da agroindústria, da tecnologia, dos bens da natureza, construindo dessa forma um novo projeto de país, afinado com necessidades do povo brasileiro ${ }^{5}$.

Além da busca originária da terra, o MST luta pela garantia de seus direitos sociais, diferenciandose por ser um movimento de massas que opta por renúncia à exploração social, política e econômica, buscando desenvolver diferentes formas de consciência 6 . Para o autor, "Sem Terra deixa de ser categoria social para se tornar nome próprio, identificando um grupo social que decidiu ser sujeito para mudar de condição social por meio da organização política”.

Mais especificamente, para este trabalho, debater o direito à saúde conjuntamente com as definições deste movimento é refletir a produção da saúde e as possíveis ações norteadoras diferenciadas, que alcancem a efetivação desse direito para a população do campo.

\section{O Movimento dos Trabalhadores Sem Terra e a saúde}

Para o MST, “o Estado deve garantir e defender a saúde de toda a população, implementando políticas públicas de soberania, segurança alimentar, de condições de vida dignas, como medidas preventivas às doenças"

O movimento defende que o SUS deve ser ampliado e melhorado, "combinando com o Programa de Saúde da Família (PSF) preventivo, incluindo o atendimento médico-odontológico e de enfermagem". Preconizam, também, o combate a todas as formas de mercantilização e transformação em objeto de lucro o atendimento à saúde, defendendo a organização pelo Estado e formações massivas dos profissionais de saúde ${ }^{8}$. Esta bandeira, definida pelo movimento, provém de uma longa discussão sobre a produção e a promoção da saúde.

Para este artigo, opta-se pelo conceito de Promoção à Saúde expresso na primeira Conferência Internacional sobre Promoção da Saúde, em Ottawa, Canadá, em novembro de 1986, que delineou conceitos baseados nos progressos alcançados com a Declaração de Alma-Ata para os Cuidados Primários em Saúde².

Deste modo, define-se:

Promoção da saúde é o nome dado ao processo de capacitação da comunidade para atuar na melhoria de sua qualidade de vida e saúde, incluindo uma maior participação no controle deste processo. Para atingir um estado de completo bem-estar físico, mental e social os indivíduos e grupos devem saber identificar aspirações, satisfazer necessidades e modificar favoravelmente o meio ambiente. ${ }^{2}$

Considerou-se importante que, a partir dessa Conferência, a saúde passa a ser vista como um 
$180 / /$

recurso para a vida, que enfatiza os recursos sociais e pessoais, as capacidades físicas e que vai além da responsabilidade exclusiva do setor saúde. Assim, para reduzir as diferenças no estado de saúde da população, as ações de promoção objetivam assegurar oportunidade e recursos igualitários para capacitar todas as pessoas a realizar seu potencial.

Para outros autores, como Dejours ${ }^{9}$, há algum tempo vem sendo debatido que saúde deixou de ser o completo estado de bem-estar físico, mental e social. Acreditam que esse estado ideal é ilusório, uma ficção, não é concretamente atingido. Para o autor, o estado de saúde não necessariamente é um estado de calma, de ausência de movimento, de conforto e de ociosidade, é justamente algo que muda constantemente. É quando se torna possível a luta contra os problemas, de tal modo que se acalme e que se resolvam os conflitos internos.

A saúde existe em diversos planos na vida dos seres humanos, independentemente de onde moram, se no campo ou na cidade. A busca pela saúde, caminha para o transformar-se de cada indivíduo, o que não é, necessariamente, acabar com a angústia dos mesmos ${ }^{9}$. Nesse sentido, o campo do trabalho e os modos de vida oferecem um campo de ação para que os trabalhadores e toda a população concretizem suas aspirações, suas ideias, seus desejos. Quando os seres de direitos têm possibilidades de escolher seu trabalho, sua organização, sua produção, abre-se um campo de aspirações flexíveis para que os trabalhadores possam adaptá-las a seus desejos, às necessidades de seu corpo e às variações de seu estado de espírito: “a saúde é quando ter esperança é permitido".

Ampliando este conceito, Ayre ${ }^{10}$ reflete sobre o alívio de um sofrimento ou o alcance de um bem-estar sempre ser mediado por saberes na interação entre dois ou mais sujeitos. Seria, neste sentido, desmistificar o conhecimento e intervenção normativas na saúde, a higiene pública e a higiene social que, cederam rapidamente lugar a uma higiene centrada na tradução cientificista e individualmente centrada das tecnologias de cuidado em saúde. Ainda que tenham experimentado um momento mais caracteristicamente coletivo, público e politicamente consensual são de conhecimento e intervenção normativas na saúde. ${ }^{10}$

Com isso, para o autor, destaca-se progressivamente a incapacidade de as ações de assistência à saúde provarem-se racionais, para se mostrarem sensíveis às necessidades das pessoas e se tornarem cientes de seus próprios limites. É a necessidade de superar a restrição da racionalidade instruída pelas ciências biomédicas e de otimizar a interação; de enriquecer novos horizontes para que a presença do outro seja afetiva; de interações intersubjetivas, ricas e dinâmicas, transpassando a conformação individualista, rumo às esferas coletivas, institucionais e estruturais de intervenção.

Completando, ter saúde não se limita a aspectos fisiopatológicos do corpo, mas assume as necessidades sociais dos indivíduos como expressão histórica do movimento e de suas potencialidades. Na medida em que as carências comprometem, motivam e mobilizam as 
pessoas, a saúde vai deixando de ser apreendida em sua dimensão individual. Se o sujeito, a partir da mobilização, passa a se constituir como "sujeito coletivo", dialogando com a construção dialética que perpassa as determinações sociais e culturais, geradas pelo modo de produção e organização da sociedade em que se inserem ${ }^{11}$.

A Política Nacional de Saúde Integral das Populações do Campo e da Floresta (PNSICF), lançada em dezembro de 2011, dialoga com essas perspectivas quando define como princípios e diretrizes a transversalidade como estratégia política e a intersetorialidade como prática de gestão norteadora. A valorização de práticas tradicionais, como reconhecimento da dimensão subjetiva, coletiva e social dos saberes tradicionais da população do campo e da floresta; a promoção de ambientes saudáveis, contribuindo para a defesa da biodiversidade; a participação social, com estímulos e qualificação dos sujeitos; entre outros, são objetivos da Política na perspectiva de diminuir as iniquidades em saúde.

\section{CAMINHO METODOLÓGICO}

Este estudo é de abordagem qualitativa, refletindo sobre a prática experimental do projeto de extensão "A Residência no campo - uma experiência com o MST", do qual a pesquisadora foi participante. Este projeto foi submetido à apreciação e aprovação do Comitê de Ética em Pesquisa da Universidade de Pernambuco (CAAE No. 14879213.2.0000.5192). Os participantes tiveram seus nomes preservados e assinaram inicialmente o Termo de Consentimento Livre e Esclarecido, no qual declaram que compreenderam e ficaram cientes da possibilidade de produções acadêmicas a partir das atividades realizadas. Este projeto foi de iniciativa dos residentes em saúde dos programas de Residência Multiprofissional das Universidades Federal e Estadual de Pernambuco e do Centro de Pesquisas Aggeu Magalhães, contando também com a participação de um estudante da Universidade Federal Rural de Pernambuco.

Foram realizadas vivências quinzenais com os assentados, oficinas de formação com o MST, reuniões dos residentes e com a Secretaria de Saúde do Município. Foram feitas relatorias de todas as atividades realizadas e um diário de campo da pesquisadora. Para este estudo, foram analisados, além das relatorias e do diário de campo, outros documentos como o Diagnóstico Rural Participativo (DRP), dados da ficha A das famílias e o Plano de Desenvolvimento do Assentamento (PDA), em um número de 30 documentos selecionados de um total de 96 relatorias e documentos produzidos pelo Projeto de Extensão, e 8 relatórios de diário de campo ${ }^{12}$.

Os documentos e relatorias foram analisados, de acordo com Bardin ${ }^{13}$, em três etapas: pré-análise, com a escolha dos documentos a serem submetidos de acordo com a formulação de hipóteses e dos objetivos a serem atingidos; a exploração do material: leitura e seleção nas relatorias do conteúdo de acordo com os temas pré-definidos; e o tratamento dos resultados juntamente com sua interpretação.

Para o tratamento dos resultados, foi utilizado o quadro sinóptico, metodologia esta em que 
primeiramente se categoriza o conteúdo selecionado de acordo com sua ordem semântica, ou seja, o tema. Dentre os temas mais discutidos nas relatorias dos encontros presenciais no assentamento, quatro quadros sinópticos foram pré-formulados, agrupando estes temas mais aparentes: gênero; educação; movimento social e assentamento; promoção à saúde. Devido à relevância e à grande quantidade de conteúdo para os objetivos da pesquisa, somente um deles foi explorado (Promoção à saúde).

O quadro possibilitou agrupar as seleções de conteúdo de acordo com o tema, a fim de explorar o material e obter um resumo geral de cada subtema para ser analisado de acordo com referenciais teóricos específicos. Para isso, foi utilizada a regra de pertinência: "os documentos retidos devem ser adequados enquanto fonte de informação, de modo a corresponderem ao objetivo que suscita a análise" ${ }^{13}$. Assim, a divisão dialogou com os princípios e estratégias da promoção em saúde (Política Nacional de Promoção à Saúde), com as bandeiras de luta do movimento social em questão, conjuntamente com a Política Nacional de Saúde Integral das Populações do Campo e da Floresta. Delimitou-se então os subtemas em três categorias: trabalho em grupo, identidade camponesa (Organização); percepção da saúde pelos assentados, lazer, alimentação, plantas medicinais, alcoolismo e doenças e assistência, a fim de observar o conceito ampliado de saúde (Produção em Saúde); água, agrotóxico, lixo (Identidade e Lutas).

\section{O Diagnóstico Rural Participativo (DRP)}

Esta metodologia utilizada foi de relativa importância para o projeto, pois possibilitou analisar conjuntamente com os assentados o foco das intervenções em produção em saúde realizada na primeira etapa (seis primeiros meses) dedicadas ao diagnóstico e ao conhecimento da população com as quais se iria trabalhar. Para o DRP, em específico, estudou-se a Cartilha do Instituto Internacional de Educação do Brasil (IEB), desenvolvida por Faria \& Neto ${ }^{14}$ no "Programa deApoio ao Desenvolvimento Institucional e Sustentável - PADIS" - com o objetivo de apoiar iniciativas, articulações e parcerias locais, voltadas para o enfrentamento de problemas socioambientais. De acordo com os autores, não há diálogos sem sujeitos, sem aqueles que se expõem e se dispõem às trocas, deste modo, o DRP viabiliza ferramentas para compor os diálogos por meio da mediação dos participantes no planejamento e/ou monitoramento de ações ${ }^{14}$.

O Diagnóstico Rural Participativo possibilita trabalhar com uma linguagem comum ao grupo de discussão, permitir a participação de alfabetizados ou não, num mesmo grupo, facilitar o diálogo entre os participantes e destes com a equipe de pesquisadores. Também, tem como objetivo despertar a discussão sobre problemas e potencialidades da realidade em questão, permitir o levantamento e a análise do conhecimento coletivo, trabalhar com as percepções das pessoas que residem no local, facilitar a verificação de informações obtidas no processo de diagnóstico e utilizar materiais que são conhecidos como folhas, sementes, papel, etc ${ }^{14}$. 
As principais ferramentas utilizadas nos dois encontros dedicados ao DRP no assentamento foram: mapa falado (trata-se de um desenho representativo do espaço ou território que está sendo objeto de reflexão); calendário sazonal (construção de uma tabela na qual um dos eixos é sempre o tempo, dividido em meses ou dias, e vão sendo inseridos elementos simbólicos e de variação significativa naquele período em questão); matriz FOFA (os participantes apontam suas fortalezas, oportunidades, fraquezas e ameaças do assentamento); jogo dos gêneros (casais escolhidos no grupo respondiam perguntas de tarefas realizadas no cotidiano, a fim de pontuarem o gênero que mais responde sim para a tarefa realizada); fluxo de produção (debate sobre os produtos cultivados, desenhando um fluxo de para quem vendem, quem colhe, e o que dá mais dinheiro e todas as suas questões envolvidas); matriz de prioridades (lista dos fatores e situações que ocorrem no assentamento, referente à necessidade de mudanças para a boa sobrevivência de todos) $)^{14}$.

\section{$O$ assentamento}

O Assentamento de Jaboatãozinho foi o escolhido para a realização do projeto, quando residentes em saúde (saúde da família e saúde coletiva), em discussão com o Setor de Saúde do MST do Estado de Pernambuco, debateram as condições facilitadas de transporte e as poucas ações de saúde na região.

O assentamento Jaboatãozinho está localizado no município de Moreno, na microrregião metropolitana do Recife, a $42 \mathrm{~km}$ da capital de Pernambuco. Como informado no Plano de Desenvolvimento do Assentamento (PDA) ${ }^{12}$ faz limite ao Norte, ao Sul, ao Leste e a Oeste com engenhos de cana-de-açúcar. A população é de aproximadamente 300 pessoas, 72 famílias e 22 agregados. De acordo com a relatoria $\mathrm{n}^{\mathrm{0}} 3$, "o acesso ao assentamento, em relação à capital (Recife), dispõe de três conduções urbanas diferentes, no caso dois ônibus e ou moto táxi, na última parte do percurso. Internamente, as casas são distantes uma das outras, necessitando de ônibus (linha municipal) ou transporte privado para se locomover"12.

A partir disso, explorou-se através de reuniões com os representantes do assentamento e alguns moradores o contato inicial, que aceitaram desenvolver conjuntamente um projeto de extensão baseado na perspectiva de educação popular para explorar e criar diferentes formas de produzir e pensar saúde. É através destas ações que esta pesquisa analisará os meios de produção em saúde desta população.

\section{RESULTADOS E DISCUSSÃO}

\section{Organização}

De acordo com o diagnóstico rural participativo realizado na primeira etapa do projeto, destacouse como problemática principal a falta de trabalho coletivo, pois se identificou que, por meio dele, 
muitas soluções para os principais problemas listados poderiam ter andamento, se trabalhassem em grupo e discutissem com mais frequência. Nessas discussões, muitas falas descreveram a necessidade do trabalho em grupo:

"sabemos trabalhar para o engenho, para o patrão, mas nunca para nós"; "ninguém quer saber de nada”; "quando tem mutirão as pessoas não participam, vocês que vem de fora dão mais valor do que os daqui de dentro"; "a ideia de cooperativa nunca foi pra frente”; " as mulheres não se reúnem”; "ninguém se preocupa com os outros, falta parceria. Mas como fazer isso? Não da pra obrigar ninguém”; "estamos acomodados” [...]

$\left(\text { Relatório DRP n }{ }^{\circ}\right)^{12}$

E quando houve a pintura do casarão do assentamento, realizada pelo MST, um dos principais questionamentos surgiu perante esta problemática: "vocês de fora vem aqui fazer algo pra "nóis", coisa que "nóis" deveria estar fazendo" (Assentado- diário de campo n9).

Devido a essa situação, foi desempenhado um trabalho com objetivo principal desta temática, através de um assunto em comum com a situação do campo e a saúde: hortas coletivas de plantas medicinais, na intenção do resgate e fomento das relações e construções comunitárias entre as famílias do assentamento, que vivem isoladas cada qual em sua parcela de terra.

Observamos que,

“apesar do reconhecimento de alguns assentados pelo projeto, onde destacaram a grande importância das atividades, já que estava reunindo as pessoas para discutirem e sentirem a necessidade da mudança, lembraram que o trabalho em Jaboatãozinho ainda se organiza de forma muito individual"; $\left(\text { Relatório DRP n }{ }^{\mathrm{o}}\right)^{12}$;

"Observou-se que um dos assentados trabalhou sozinho em uma das hortas";

(Diário de campo $\left.n^{\mathrm{o}} 22\right)^{12}$;

"Houve o reconhecimento da responsabilidade das famílias onde foram realizadas as oficinas em serem multiplicadoras das ações realizadas durante toda a execução do projeto e sobre as hortas de plantas medicinais e que era necessário existir uma motivação, uma necessidade vinda das próprias pessoas, e que mesmo assim é difícil de acontecer e de mudar, motivar novas atitudes para que as pessoas se engajassem 
nas atividades";

(Diário de campo $\left.\mathrm{n}^{\circ} 26\right)^{12}$

Deste modo, pode-se trabalhar a temática de trabalho grupal relacionado às hortas comunitárias na perspectiva de que a Promoção à Saúde traz como diretriz na Carta de Ottawa $(1986)^{15}$, o trabalho através de ações comunitárias, desenvolvendo prioridades e estratégias, tomadas de decisão, visando à melhoria das condições de saúde. Dado que os próprios assentados questionaram suas problemáticas em relação às condições de vida, observaram que dentro do próprio assentamento há dificuldades de mobilização e organização para o trabalho em conjunto.

Esse ponto foi observado ainda como desafio para o Movimento dos Trabalhadores Sem Terra, quando descrevem no Programa Agrário do VI Congresso Nacional do $\mathrm{MST}^{8}$, na proposta de um Programa de Reforma Popular, a necessidade de organizar a produção com base em todas as formas de cooperação agrícola como mutirões, associações, cooperativas, empresas públicas e cooperativas de prestação de serviço (p. 39) ${ }^{8}$, o que dependeria essencialmente das mobilizações e ações em conjunto de um assentamento. Porém, se não existem mobilizações ou interesse para soluções das condições de vida dos próprios assentados, como trabalhariam de forma conjunta para melhorar seus meios de produção?

Azevedo \& Pelicioni ${ }^{16}$ descrevem, em seu artigo sobre promoção da saúde e agroecologia, a dimensão social de modernização do meio rural que não se ajustou às condições da agricultura familiar, pois reduziu o conhecimento agrícola tradicional, bem como seus hábitos de vida, que foram desvalorizados. Também foi refletido por Stedile ${ }^{17}$, nos textos de formação sobre a questão agrária, que há a necessidade de resistência de toda a comunidade camponesa, como classe que defende seu espaço territorial frente aos interesses do capital para poder sobreviver e resistir. Nas suas palavras, "a força das organizações camponesas não se mede por seus programas ou pela justeza de suas propostas e ideias, a força dos camponeses se mede pela capacidade que tiveram de reunir muita gente, em torno do mesmo objetivo, juntar número de pessoas. E juntar muita gente é fazer luta de massa" $"$.

\section{Produção em saúde}

O objetivo geral do projeto em questão foi trabalhar práticas que viabilizassem novos pensamentos em saúde no campo, conjuntamente com o saber dos assentados, tendo em vista que são agentes multiplicadores de saúde, eliminando a perspectiva vertical e de apenas garantir assistência às doenças, ou seja, buscando enfatizar as condições de vida. Essa questão foi problematizada entre os assentados que questionaram: "tem gente aqui que nunca foi no médico, não cuidam dos dentes" (Assentado) 12; "necessidade do serviço odontológico e com crianças, onde o projeto neste formato não serviria" (Relatoria $\left.n^{\mathrm{o}} 7\right)^{12}$. 
Refletindo sobre o cotidiano dos assentados, o projeto também reforçou a criação de atividades de lazer visando "melhorar a convivência entre os mesmos, a intenção era reativar os momentos de encontro, confraternização, que pudessem fortalecer os vínculos comunitários" (Relatoria $\mathrm{n}^{\circ}$ 13) ${ }^{12}$. Foram realizadas atividades como exibição de filmes, grupo de teatro - Caravana Tapioca ${ }^{3}$, seguido de reflexão e debates com os assentados. Estes "recordaram que um antigo morador tocava e muitos ficavam ali conversando e cantando noite adentro" (Diário de campo $\mathrm{n}^{\mathrm{o}} 16{ }^{12}$. $\mathrm{Na}$ apresentação de teatro, "apareceram moradores que nunca apareciam nas reuniões, a escola ficou lotada, houve muitas risadas" (Relatoria $\mathrm{n}^{\mathrm{o}} 25$ ) $^{12}$. E nas discussões e buscas pelos depoimentos "refletiram que gostariam de ter aquilo mais vezes e que o casarão poderia ser um espaço em potencial de cultura, que aquilo também era saúde, ser feliz" (Diário de campo n²6) ${ }^{12}$.

Outro aspecto relevante ao cotidiano foi a alimentação, pois as atividades realizadas aos fins de semana intensificavam as vivências, nas quais os residentes dormiam na casa dos assentados, a fim de trocar experiências fora da realização das atividades e também presenciar o modo de vida, ser e estar no mundo como camponês. Foi possível observar "alimentação pouco variada, sem consumo de frutas, verduras, legumes naturais, mesmo que o acesso aconteça pelas feiras do município e outros próximos dali, para produção, compra e comercialização" (Relatoria $\left.n^{\circ} 10\right)^{12}$. Em algumas casas, havia muita utilização de temperos prontos, miojo e carnes com gordura, frango e peixes fritos no café-da-manhã, no discurso de que a comida tem que ser forte e ter sustento, se não, não consegue trabalhar (Relatorias n ${ }^{0} 20,21$, Diário de campo $n^{0} 22$ e 26) ${ }^{12}$.

Contudo, a assistência em saúde também foi um aspecto observado na convivência em Jaboatãozinho. Presenciou-se "um dos jovens adoecido, que foi levado para o hospital de ambulância, mesmo não sendo grave, mas por não existir outra possibilidade" (Relatoria $n^{\circ}$ 20) ${ }^{12}$. Em reunião com a Secretaria de Saúde do município, as doenças negligenciadas foram as principais citadas, devido ao grande número de leishmaniose e esquistossomose identificadas durante as vivências: "outra assentada mostrou suas feridas devido à leishmaniose e disse que tomou 30 dias de injeções para se curar" (Diário de campo no 22 ) $^{12}$. E "o posto de saúde foi eleito pelos moradores como a principal melhoria que eles necessitavam", de acordo com o Diagnóstico Rural Participativo $n^{\mathrm{o}} 2^{12}$.

Na atenção Primária:

"o assentamento tem cobertura de uma Unidade de Saúde da Família com uma das assentadas sendo a Agente Comunitária de Saúde há 14 anos. Ela relatou que são 92 famílias cadastradas (300 pessoas com os agregados) e a principal dificuldade é o acesso e a distância entre as casas e destas com a USF (a USF mais próxima se encontra a 4km de distância do assentamento no município de Massaranduba), o que inviabiliza a

3 Caravana Tapioca formada por uma dupla de palhaços circenses que trabalham com o apoio do Ministério da Cultura, FUNARTE e governo Federal.

// Tempus, actas de saúde colet, Brasília, 8(2), 173-194, jun, 2014.

ISSN 1982-8829 
realização efetiva de seu trabalho."

$\left(\text { Relatoria } n^{\circ} 6\right)^{12}$

Com informações diretas da ficha A das famílias, observou-se:

"Em conversa com a mesma, relata que as mulheres têm pouca adesão aos exames de prevenção, há grande quantidade de hipertensos (43), em situações de emergência recorrem ao telefone público para ambulância os atender, as doenças prevalentes são leishmaniose, esquistossomose e alcoolismo (25), e as campanhas de vacinação são feitas no assentamento.

A rede Inter setorial, apesar de existir, se localiza basicamente em outros municípios: Centro de Referência da Assistência Social - CRAS e o Centro de Especialidades Odontológicas - CEO em Moreno, já a Maternidade, policlínica e hospital mais próximos se localizam em outro município.”

$\left(\text { Relatorias } n^{\circ} 6\right)^{12}$

Outro fator de relevância na assistência foi a presença de alcoolistas nessa população. Um dos assentados relatou sofrer de sintomas, mesmo já tendo parado de beber "em processo de abstinência sofre com os sintomas (agressividade, alucinações e tremores)" (Relatoria $\mathrm{n}^{\mathrm{0}} 7$ ) $^{12}$. E outro assentado que, para realizar atividades do projeto, "G. estava alcoolizado" (Relatoria $\left.\mathrm{n}^{\mathrm{o}} 20\right)^{12}$.

Assim, as hortas coletivas de plantas medicinais foram o tema escolhido para a segunda etapa do projeto (os seis últimos meses), devido à observação de que:

"Havia cultivo com ervas e plantas medicinais em uma pequena parte do quintal de vários assentados"

$\left(\text { Relatoria } \mathrm{n}^{\mathrm{o}} 10\right)^{12}$

"eu planto pra dar pros outro, o homi que tá com muita gordura no sangue, plantei e separei pra ele"

$\left(\text { Assentada - diário de campo } \mathrm{n}^{\mathrm{o}} 22\right)^{12}$

O tema foi discutido e definido após avaliação e apresentação do Diagnóstico Rural Participativo com os assentados: "muitos sabiam dizer o uso, como cultivavam, em sua maioria babosa, capim santo, erva cidreira, boldo, com empolgação relataram casos familiares - meu avô 
já curou até epilepsia, só com as plantas" (Assentado - relatoria $\left.\mathrm{n}^{\mathrm{o}} 14\right)^{12}$. Contudo, a maioria assumiu não dar muita importância para as plantas porque não repassavam este conhecimento para seus filhos, assim como esse conhecimento foi adquirido. Reconheceram que a valorização do plantio simples da terra não acontece, pois compram os mesmos produtos no mercado e na feira, quando já tem no próprio quintal (Relatorias $n^{0} 15,27$ e Diário de campo $\left.\mathrm{n}^{\mathrm{o}} 16\right)^{12}$.

Por meio destes dados, foi observado que, mesmo o assentamento possuindo uma Agente Comunitária de Saúde, a mesma tem dificuldades de acesso pelas casas serem distantes uma das outras, além de a USF de referência ser de difícil acesso. Assim, mesmo havendo cobertura sistemática pela atenção primária do SUS, o acesso da população não necessariamente é garantido, muito menos a sua adesão aos programas e atendimentos fornecidos. Este fato pode acontecer com comunidades do campo, quando a equipe como um todo (ACS, enfermagem, médicos e odontólogos) não se aproximam dos costumes e dificuldades desta população, não criando vínculos e parcerias para que sinta-se acolhida e apoiada pela equipe de saúde. Esse princípio aparece como diretriz na PNIPCF (2012), quando se preconiza a valorização de práticas e conhecimentos tradicionais, com o reconhecimento da dimensão subjetiva dessas populações e a garantia da informação e comunicação em saúde, prezando pela diversidade cultural.

O fato de os assentados estarem distantes dos mecanismos de assistência à saúde aparece também no estudo de Bohes \& Fernandes ${ }^{18}$, que aponta como um elemento de determinação para a saúde o isolamento geográfico de áreas rurais, acessibilidade limitada, que agrava a situação de saúde dos indivíduos. Esse estudo buscou compreender a prática de cuidado pelas enfermeiras em áreas rurais, classificada como um desafio,

pelo fato de encararem diversas estruturas, culturas, crenças e valores, exigindo negociação do saber profissional com famílias de complexas dinâmicas e de diferentes gerações (...) conhecer a influência da localização geográfica, da condição econômica, do trabalho, da etnicidade e do gênero na saúde das famílias.

Uchoa et al $^{19}$ também descreve, em seu artigo sobre a satisfação do Programa de Saúde da Família em dois municípios na zona rural do Rio Grande do Norte, que os principais problemas em saúde foram relacionados às doenças crônicas como hipertensão e diabetes e a incorporação de uma concepção de necessidades de saúde centrada na doença. Analisa a falta de iniciativas multidisciplinares e intersetoriais como enfrentamento das condições adversas daquela população.

A identificação de elementos chave das condições de vida da população é uma prioridade na implementação de estratégias de assistência que, nas limitações dos profissionais, não necessariamente intensificam iniciativas de saúde e produção de vida da população com especificidades, ficando apenas na visão vertical da assistência e no enfrentamento de doenças. Processos paralelos devem acontecer, porém, a adesão dos usuários do campo, o trabalho de // Tempus, actas de saúde colet, Brasília, 8(2), 173-194, jun, 2014. 
promoção de saúde e as ações assistenciais podem complementar-se. Enquanto prática de atenção primária, incorporam-se à perspectiva de Educação Popular em Saúde.

Essa perspectiva, já em 2012, foi concretizada na Política de Educação Popular em Saúde $(\mathrm{PNEP}-\mathrm{SUS})^{20}$, que preconiza processos educativos intencionalmente direcionados à promoção da autonomia das pessoas, entre os saberes populares e técnicos-científicos, a cidadania, a violência, a opressão. Para que o cuidado em saúde se fundamente em uma estratégia singular, processos que busquem a formação, a produção de conhecimentos, a intersetorialidade e a democratização do SUS devem incluir a educação que não se faça "para" o povo, mas ao contrário, "com” o povo.

No estudo de Lara et $\mathrm{al}^{21}$ sobre os aspectos culturais das práticas dos Agentes Comunitários em Saúde em áreas rurais em Minas Gerais, aparece o fato de a prática de educação em saúde na Estratégia de Saúde da Família (ESF) utilizar saberes e costumes populares relacionados à utilização de chás e ervas medicinais, eventualmente conciliados com as terapias medicamentosas e prescrições biomédicas. Os autores relatam que se concretiza o desenvolvimento das prioridades na tomada de decisão e definição de estratégias, visando à melhoria das condições de saúde e o desenvolvimento do empowerment comunitário, no processo saúde doença da comunidade local. São experiências compartilhadas de culturas herdadas que exercem influências sobre as atividades cotidianas da população, "tornando possível o desenvolvimento de ações de promoção da saúde e prevenção de doenças" ${ }^{21}$.

\subsection{Identidade e lutas}

Foi observado que algumas características da maioria dos assentados ainda se apresentam enfraquecidas como: as relações de cooperação, organicidade para luta de seus direitos constitucionais não assegurados, falta de interesse em reuniões, disponibilidade, comunicação, o que reforça a invisibilidade no campo (Relatoria $\left.\mathrm{n}^{\mathrm{o}} 13\right)^{12}$.

Alguns desses aspectos influenciam costumes cotidianos e modos de vida dos assentados. Como o lixo que "na maioria das casas ainda era queimado. Uma das assentadas ainda jogava o lixo pela janela, mesmo prometendo à R., liderança do local, que iria queimá-lo" (Relatoria $\left.n^{0} 21\right)^{12}$. Para a preparação da horta de plantas medicinais, havia o lixo espalhado pelo local e o assentado que mora próximo dali, disse "o lixo não faz mal ao solo", contudo muitos argumentaram que o tempo de decomposição demoraria e, por isso, precisariam recolhê-lo, e todos participaram da tarefa (relatoria $\left.\mathrm{n}^{\mathrm{o}} 20\right)^{12}$.

Outro exemplo é a presença de alguns direitos, que ainda não são totalmente garantidos, mesmo em 15 anos de assentamento, como o acesso à água e a pouca mobilização para tal:

"No assentamento, há um rio que cruza quase todas as parcelas, porém, não abastece a casa dos moradores e nem é utilizado para irrigação, isto somente se o assentado, 
por condições próprias fizer mecanismos para tal, como a compra de bombas. Como exemplo, a casa de M. utiliza água de cacimba da parcela do vizinho e não tem água encanada, assim como a escola municipal."

(Diário de Campo no $^{1}$ e 26) ${ }^{12}$

No mesmo sentido acontece com os agrotóxicos, quando se comprovou que a maioria dos assentados ainda os usa e não consegue construir uma alternativa a eles. A relatoria $\mathrm{n}^{\mathrm{o}} 10$ mostrou que "muitas famílias visitadas no assentamento utilizam o monocultivo (cana-de-açúcar), queima e agrotóxicos para revender às usinas mais próximas". No caso da mandioca, também utilizam fertilizantes. Uma das assentadas tinha grande quantidade de fertilizantes químicos guardados na varanda de sua casa, pois a terra não respondia mais sem ele (Relatoria 14) ${ }^{12}$ Com consciência, relatou "o grande beneficiário é a indústria, pois a cada ano a quantidade de fertilizante necessária para terra produzir aumenta" (Diário de campo $\left.\mathrm{n}^{0} 26\right)^{12}$. São poucas as famílias que cultivam alimentos frutíferos para comercialização e para o próprio sustento.

Miranda et $\mathrm{al}^{22}$ conclui, em seu estudo sobre o neoliberalismo e os agrotóxicos, que a adoção dos princípios do neoliberalismo norteadores do modelo de desenvolvimento do Brasil, a partir da década de 90, apenas prioriza o atendimento aos compromissos internacionais, especificamente ao capital financeiro, permanecendo a propriedade de terra em grandes latifúndios, reforçando a incorporação tecnológica, expulsando trabalhadores do campo, associados à falta de investimentos na infraestrutura básica para a população.

Desse modo, os poucos camponeses que sobrevivem no Brasil em busca de uma vida melhor acabam como resume Rigotto et $\mathrm{al}^{23}$ em seu estudo, caracterizando-se de acordo com a classificação descrita:

alguns (camponeses) se tornam "parceiros" das grandes empresas para ter delas a possibilidade de comercialização (que uma política pública poderia oferecer) e assim recebem a imposição de um pacote tecnológico que inclui os mesmos agrotóxicos, sem contar, entretanto, com o aporte técnico para proteger seus familiares ou seus poucos empregados. ${ }^{23}$

De algum modo, a superação desta prática pode acontecer com o envolvimento com lutas comunitárias, como neste estudo da autora. Em processo de luta contra a contaminação da água, foram demonstrados, em sua pesquisa, os riscos e os impactos à saúde humana, em audiências públicas na Câmara Municipal, na Assembleia Estadual, na Chapada do Apodi, no Rio Grande do Norte, que resultou na proibição da pulverização aérea no município, onde a participação ativa do movimento intensificou a luta, principalmente após o assassinato de um líder comunitário.

Portanto, pensar em intensificar diferentes formas de produção agrícola e organizações de lutas 
para a busca dos direitos à infraestrutura no campo e incentivos é também produzir saúde, visto que a falta deles, como apresentado, prejudica as condições de promoção à vida.

Pelicioni \& Azevedo ${ }^{24}$ debatem algumas alternativas para estes modelos agrícolas por meio da agroecologia, como fortalecimento da possibilidade de o agricultor familiar se manter no meio rural com dignidade, conservação ambiental, minimizando gastos e o transporte de alimentos. Destacouse também a questão do sabor do alimento produzido "que deve ser diferente, mais gostoso" 24 , pois não utiliza nenhum tipo de produtos bioquímicos.

Esse é um debate que deve ser ampliado quando se discute promoção à saúde no campo e seus meios de produção. Quais são as formas alternativas existentes que os agricultores podem exercer para produzir melhor, com bem estar e autonomia, na sua conexão com a terra? Até que ponto profissionais da saúde entram em contato com esses determinantes?

O próprio Movimento dos Trabalhadores Sem Terra tem, como alguns de seus principais compromissos, ratificados no VI Congresso do MST, em fevereiro de $2014^{8}$, priorizar a produção de alimentos saudáveis à saúde dos produtores e dos consumidores e à preservação da natureza; produção agrícola agroecológica com a abolição do uso de agrotóxicos; e a terra, água, flora e fauna, minérios e sol devem estar a serviço do povo e preservados para as gerações futuras. Esse é um debate que o Movimento deve ampliar para com os órgãos e os responsáveis pela saúde. No documento, identifica-se a saúde como um dos cernes principais da construção pela Reforma Agrária Popular: o campo como um local de bom viver, com direitos respeitados e condições dignas de vida, tendo em vista que a transformação social se insere como compromisso de luta, não só dos camponeses, mas de toda a sociedade ${ }^{8}$.

\section{CONCLUSÃO}

Pode-se observar, por meio deste estudo, características específicas da população do campo inerentes a uma concepção de vida que tem como elemento norteador a possibilidade de mobilização e luta em um movimento de massa. Características estas que passaram a ser preconizadas e observadas pela saúde com mais atenção pela Política Nacional Integral em Saúde das Populações do Campo e da Floresta.

Ao expor as formas de cuidado de um assentamento específico, observou-se que ainda existem poucos investimentos na saúde dos camponeses, principalmente por serem os que sofrem as principais influências de uma escolha neoliberal capitalista de um país que prejudica a vida do pequeno agricultor na forma de produzir, se manter e realizar de forma autônoma sua produtividade econômica, social, cultural e, principalmente, de saúde e vida.

Ressalta-se a necessidade de organização política e de grupos em assentamentos relacionados ao Movimento dos Trabalhadores Sem Terra, que, mesmo tendo seus princípios e diretrizes contra- 
$192 / /$

hegemônicos, ainda buscam ampliar o debate sobre os meios de melhorar e criar condições de vida que se atentem de forma holística para a saúde, para além de uma luta classista contra a propriedade de terras, mas que não se distanciem de sua base, fomentando novas possibilidades de produção da saúde.

Outro aspecto relevante é o papel do profissional em saúde, mais especificamente do Residente em Saúde, no contato com as particularidades da população do campo, que, ao se aproximar destes, podem se sensibilizar, criar e fomentar produções em saúde voltadas para a relação com a natureza, respeitar diferentes costumes e dialogar com a produção de novos meios de serviço e atendimento à saúde no campo, por meio da Educação Popular. Ratifica-se a necessidade de ampliação acadêmica, de serviços e estudos nesta área pelos profissionais de saúde que, ao utilizar Programas de Residência como educação permanente no SUS, podem fomentar produções específicas, na perspectiva de ressignificação da saúde nos assentamentos e da construção de outros projetos como uma Residência Multiprofissional e Interdisciplinar de Saúde no Campo, ainda inexistente em nosso país.

\section{REFERÊNCIAS}

1. MARTINS, J. de S. Expropriação e Violência - A questão Política no Campo. São Paulo: Hucitec, 1991.

2. Brasil. Ministério da Saúde. Secretaria de Gestão Estratégica e Participativa. Departamento de Apoio à Gestão Participativa. Política Nacional de Saúde Integral das Populações do Campo e da Floresta / Ministério da Saúde, Secretaria de Gestão Estratégica e Participativa, Departamento de Apoio à Gestão Participativa. , 1. ed.; 1. reimp. , Brasília : Editora do Ministério da Saúde, 2013.

3. STEDILE, J. P.; Coletânea de textos da ENFF n. 10: as tendências do capital na agricultura e os desafios do Movimento Camponês da América Latina; São Paulo, outubro de 2011.

4. COHN, A. Estado e sociedade e as reconfigurações do direito à saúde. Ciênc. Saúde coletiva (online). 2003, vol.8, n.1, PP. 09 - 18.

5. Programa agrário do MST, Texto em construção para o VI Congresso, 2013. 29-34. Site visitado em 25 de março de 2014: http://www.mst.org.br/node/7713

6. BOGO, A. O MST e a Cultura, - Movimento dos Trabalhadores Sem Terra, São Paulo, 3. Ed, 2009.

7. Site visitado em 25 de março de 2014: http://www.mst.org.br/node/7713 
8. Programa Agrário do VI Congresso Nacional do MST, Cap. a proposta de um Programa de Reforma Popular, 2014.

9. DEJOURS, C. Por um novo conceito de saúde. Revista brasileira de Saúde Ocupacional. N. 51 - vol. 14 - abril, maio junho, 1986.

10. AYRES, J. R. C. M. Care and reconstruction in healthcare practices, Interface - Comunic., Saúde, Educ., v.8,n.14, p.73-92, set.2003-fev.2004.

11. SilVA, J. P. V. da S.; BATISTELlA, C.; GOMES, M. de L.; Problemas, Necessidades e Situações de Saúde: uma revisão de abordagens para a reflexão e ação da equipe de saúde da família. In: O território e o processo saúde -doença; Educação Profissional e docência em saúde: a formação e o trabalho do agente comunitário - Fundação Fiocruz e Escola Politécnica Joaquim Venâncio, cap17, 2008.

12. Relatorias e documentos do Projeto de Extensão: "A RESIDÊNCIA NO CAMPO - UMA EXPERIÊNCIA COM O MST"; Coordenação de Saúde da Família - Faculdade de Medicina da UPE in: Rua Arnóbio Marques, 310 Sto Amaro - Campus Universitário, cep 50.100-130 - tel: (81) 3183-3528.

13. BARDIN, L. Análise de Conteúdo, ed. 2011p 125-279.

14. CUNHA, F. A. A. da.; NETO, P. S. F.; Ferramentas do diálogo - qualificando o uso das técnicas do DRP: diagnóstico rural participativo - Brasília: MMA; IEB, 2006. 76 p. : il. color ; $23 \mathrm{~cm}$.

15. site visitado em 25 de março de 2014: http://bvsms.saude.gov.br/bvs/publicacoes/carta ottawa.pdf

16. AZEVEDO, E. M. de; PEliCIONI, M. C. F.; Promoção da Saúde, Sustentabilidade e Agroecologia: uma discussão intersetorial; Saúde Soc. São Paulo, v.20, n.3, p.715-729, 2011.

17. STEDILE, J. P.; Parte 4 - Reflexões sobre as tendências do capital na agricultura e os desafios do Movimento Camponês da América Latina; in: MARTINS, H.; CALANZAS, M.; STEDILE, J. P.; Questão Agrária contemporânea e os movimentos camponeses da América Latina Coletânea de textos da ENFF nº 10, São Paulo, out. 2011.

18. BOHES, A, E.; FERNANDES, G. C. M.; Contribuições da literatura para a enfermagem de família no contexto rural; Texto Contexto Enferm, Florianópolis, 2011 Out-Dez; 20(4): 803-11.

19. UCHOA, A. da C.; SOUZA, E. L.; SPINELli, A. F. S.; MEDEIROS, R. G. de; PEIXOTO, D. C. de S., SILVA, R. A. R. da; ROCHA, N. de S. P.; Avaliação da satisfação do usuário do 
$194 / /$

Programa de saúde da Família na zona rural de dois pequenos municípios do Rio Grande do norte; Physis Revista de Saúde Coletiva, Rio de Janeiro, 21 [ 3 ]: 1061-1076, 2011.

20. BRASIL, Ministério da Saúde; Política Nacional de Educação Popular em Saúde; Brasília - DF, 2012.

21. LARA, M. O.; BRITO, M. J. M.; REZENDE, L. C.; Aspectos culturais das práticas dos Agentes Comunitários de Saúde em áreas rurais; Rev Esc Enferm USP 2012; 46(3):673-80 www. ee.usp.br/reeusp/, 2011.

22. MIRANDA, A. C. de; MOREIRA, J. C.; CARVALHO, R. de; PERES, F; Neoliberalismo, uso de agrotóxicos e a crise da soberania alimentar no Brasil; Ciência \& Saúde Coletiva v. 12 n. 1 janeiro / março 2007 ISSN 1413-8123. p. 7-13.

23. RigOtTO, R. M.; CARnEIRO, F. F.; MARINHO, A. M. C. P.; ROCHA, M. M.; FERREIRA, M. J. M.; PESSOA, V. M.; TEIXEIRA, A. C. de A.; SILVA, M. de L. V. da;

BRAGA, L. de Q. V.; TEIXEIRA, M. M.; O verde da economia no campo: desafios à pesquisa e às políticas públicas para a promoção da saúde no avanço da modernização agrícola; Ciência \& Saúde Coletiva, 17(6):1533-1542, 2012.

24. PELICIONI, M. C. F.; AZEVEDO, E;. Agroecologia e promoção da saúde no Brasil. Rev Panam Salud Publica. 2012; 31(4):290-5.

Artigo apresentado em 07/04/14

Artigo aprovado em 23/05/14 Artigo publicado no sistema em 29/06/14 